\title{
Order effects and display persistence in probabilistic opinion revision
}

\author{
ROBERT A. EDENBOROUGH \\ $R A F$ Institute of Aviation Medicine, Farnborough, Hants, England
}

\begin{abstract}
Sixteen subjects performed a bookbag and poker-chip task. On one run ambiguous data preceded unambiguous data; on another run, unambiguous data came first For half the subjects only the current data item appeared; for the others, all preceding items were shown too. Final responses were higher when unambiguous data came last, which was interpreted as a recency effect. Whether the data persisted had no significant effect.
\end{abstract}

It has been suggested that suboptimal effects in opinion revision tasks, specifically those of the bookbag and poker-chip type, arise by the influence of artifactual variables. That is, performance is affected by aspects irrelevant to the Bayesian norm. For example, DuCharme (1970) argued that subjects were biased against making responses that appear extreme on the response scale used. This paper describes an experiment directed at investigating the formally irrelevant aspects of sample order and method of presentation.

With regard to order, primacy has been reported by Peterson and DuCharme (1967) and by Dale (1968) while Pitz and Reinhold (1968) and Shanteau (1970) have found recency. Slovic and Lichtenstein (1971) argue that which effect occurs could depend on the form of the sample data. They suggest that recency effects would generally be expected; primacy had only occurred where data had first supported one hypothesis and then switched to supporting the alternative. In this case, subjects discounted the later data.

In the present experiment, an attempt was made to manipulate sample data so that they would not be discounted. Samples were made up of an ambiguous part and a part pointing clearly to one hypothesis. The order of these parts was varied. Under primacy a higher final response should be made when the unambiguous data come first. Recency would be indicated by higher terminal responses occurring with the ambiguous half first.

Order effects might also be influenced by how the data are presented. A particular aspect examined here was the persistence of the data display, whether only the current item or all data so far are displayed. It would be predicted that a persistent, or cumulative display would tend to enhance the order effects. Primacy would be enhanced because the persistent display preserves information that could otherwise be forgotten. Thus, with both persistent and nonpersistent displays, primacy would imply higher terminal responses when the first

This paper is sponsored by Paul Slovic, who takes full editorial responsibility for it. half of the sample was unambiguous, but this effect would be greater with the persistent than with the nonpersistent display. If recency were found, when the ambiguous half is presented first the terminal response should be slightly higher with the persistent display. The effect will not be marked as the more recent items should not, in any case, be forgotten. Similarly, with the unambiguous half first, terminal responses should be slightly lower with the persistent display under recency.

\section{METHOD}

A PDP-8 computer was programmed to generate sequences of squares and crosses on a display screen. These shapes comprised the binary events in the bookbag task. Subjects' responses consisted of an indication of which shape was in the majority in the population from which the sample had been drawn, together with an estimate of how probable this was. Responses were made after each item of a twenty-item sample and were built up on the screen by means of keyboard inputs. The probability estimates could be expressed as percentage probabilities to two decimal places although, in practice, whole percentage points were most commonly used by subjects.

In the nonpersistent display condition each new sample item replaced the previous one, while in the persistent condition the twenty items were built up in a 4 by 5 block on the screen.

Subjects were 16 personnel employed at the RAF Institute of Aviation Medicine and Royal Aircraft Establishment, Farnborough, Hants, England, serving in a variety of scientific, technical and clerical grades. They were randomly assigned to two groups of eight, one group for each display condition.

Each subject performed four runs, one with each of four samples. The samples were presented to subjects in different random orders. The first 10 items of Sample 1 were drawn from a population with events in the ratio $90: 10$, while the second 10 were from a 50:50 population; i.e., an unambiguous half preceded an ambiguous half. The mean proportion was thus $70: 30$, and this was the value given to the subjects. Sample 2 was made up of the second half of Sample 1 (50:50 part) followed by the first half of that sample $(90: 10$ part). Again this sample was represented to subjects as coming from a 70:30 population. Sample 3 was drawn entirely from a 90:10 population and sample 4 from a 55:45 population, i.e., one with high and one with low diagnosticity. These were the ratio values given to the subjects. Samples 3 and 4 were regarded as 'fillers' used to reduce the possibility of subjects' becoming aware that the other two samples contained essentially the same items. They were not informed that any of the samples varied in composition from one half to another. 
The instructions were designed to insure that subjects were aware that higher population proportions implied that posterior probability estimates should be higher.

\section{RESULTS}

Final responses for the two samples with halves reversed (1) and (2) were examined by means of an analysis of variance, taking display condition, samples and their interactions into account (see Table 1).

The table shows that the only significant effect found was for samples. This effect was in terms of higher estimates for Sample 2, where the unambiguous data came in the second half, than for Sample 1, where the unambiguous data came first. The mean final estimate was 84.6 for Sample 1 and 87.1 for Sample 2. The corresponding Bayesian value was 99.9 , so that the usual conservatism effort was demonstrated.

\section{DISCUSSION}

The finding of higher terminal values for the sample in which the unambiguous data were presented last demonstrates a recency effect. This accords with Slovic and Lichtenstein's (1971) view that this is the effect to be generally expected. It also fits in with their notion that primacy is only found when samples are arranged such that later-occurring data are discounted. In Sample 1, the second half data were ambiguous rather than contradictory to those shown earlier in the sample. This seems unlikely, however, to be the last word on the primacy-recency issue. There is evidence from a study by Pitz (1969) that subjects are reluctant to make a decrease in the size of their estimate for a datum that tends to infirm their currently held hypothesis, suggesting a primacy effect independent of manipulation of the order of data within a sample.

The fact that display persistence was not found to be significant, either as a main effect or in interaction with samples, is not wholly surprising. A large effect of the display variable was predicted given that primacy was found, whereas recency actually appeared. Insofar as nonsignificant results can be said to agree, this is in agreement with a finding by Phillips, Hays, and
Table 1

Analysis of Variance of Terminal Estimates: Samples 1 and 2

\begin{tabular}{|c|c|c|c|c|c|}
\hline Source & $\mathrm{df}$ & $\begin{array}{c}\text { Sums } \\
\text { of } \\
\text { Squares }\end{array}$ & $\begin{array}{c}\text { Mean } \\
\text { Squares }\end{array}$ & $\mathrm{F}$ & $\mathrm{p}$ \\
\hline Groups & 1 & 115 & 115 & $<1$ & \\
\hline Error & 14 & 5,118 & 366 & & \\
\hline Samples & 1 & 88 & 88 & 9.8 & $<.01$ \\
\hline Samples by Group & 1 & 36 & 36 & 4 & n.s. \\
\hline Error & 14 & 126 & 9 & & \\
\hline Total & 31 & 5,483 & & & \\
\hline
\end{tabular}

Edwards (1966) that whether or not data persisted had little effect. In their experiments, data were randomly positioned, which would have made it harder to keep note of their serial position than in the persistent display condition used here. Display persistence does not seem to have been investigated by any other researchers; such evidence as there is suggests that it has little influence on probabilistic opinion revision.

\section{REFERENCES}

Dale, H. C. A. Weighing evidence: an attempt to assess the efficiency of the human operator. Ergonomics, 1968, 11, 215-230.

DuCharme, W. M. A response bias explanation of conservative human inference. Journal of Experimental Psychology, 1970, 85, 66-74.

Peterson, C. R., \& DuCharme, W. M. A primacy effect in subjective probability revision. Journal of Experimental Psychology, 1967, 73, 61-65.

Phillips, L. D., Hays, W. L., \& Edwards, W. Conservatism in complex probabilistic inference. IEEETransactions on Human Factors in Electronics, 1966, 7, 7-18.

Pitz, G. F. An inertia effect (resistance to change) in the revision of opinion. Canadian Journal of Psychology, 1969, 23, 24-32.

Pitz, G. F., \& Reinhold, H. Payoff effects in sequential decision making. Journal of Experimental Psychology, 1968, 77, 249-257.

Shanteau, J. C. An additive model for decision making. Journal of Experimental Psychology, 1970, 85, 181-191.

Slovic, P., \& Lichtenstein, S. Comparision of Bayesian and regression approaches to the study of information processing in judgment. Organizational Behaviour and Human Performance, 1971, 6, 649-744.

(Received for publication September 17, 1974.) 